\title{
Editorial
}

\section{A revista Epidemiologia e Serviços de Saúde, seu papel e contribuições no contexto pandêmico \\ doi: 10.1590/S1679-497420210004000022}

\section{Epidemiology and Health Services (Epidemiologia e Serviços de Saúde) journal, its role and contributions in the pandemic context}

\section{La revista Epidemiologia e Serviços de Saúde, su papel y contribuciones en el contexto pandémico}

\begin{abstract}
$A$ Epidemiologia tem historicamente assumido papel relevante na produção de informação para o processo de decisão no âmbito da saúde pública. Com base em seus fundamentos e por meio da aplicação de seus métodos, tem contribuído para a melhor compreensão dos fenômenos de saúde da coletividade e fornecido informações que auxiliam os gestores e profissionais dos serviços no processo de tomada de decisão, permitindo a definição de políticas, intervenções e práticas voltadas à prevenção, ao monitoramento e à redução do impacto de eventos de saúde na população. ${ }^{1}$
\end{abstract}

No Brasil, a epidemiologia experimentou expressivo desenvolvimento a partir da década de 1980, e sofreu forte impulso nos seus campos científico e prático, com a redemocratização do país e a promulgação da Constituição Federal de 1988. ${ }^{2}$ Desde então, esta disciplina, forjada no compromisso com a redução das iniquidades de saúde e a melhoria das condições de vida da população brasileira, ${ }^{2}$ tem fornecido contribuições relevantes para 0 conhecimento dos processos saúde-doença, o diagnóstico da situação de saúde da população, para a definição de políticas de saúde e de práticas voltadas ao enfrentamento dos problemas de saúde. Cita-se como exemplo recente o protagonismo e dinamismo de cientistas e profissionais da área no enfrentamento da emergência global da epidemia de Zika no Brasil, que, com a cooperação de centros de pesquisas e instituições governamentais nacionais e internacionais, conseguiu prover, em curto período de tempo, evidências epidemiológicas sobre a relação entre a epidemia de microcefalia e a infecção pelo vírus, ${ }^{3}$ elaborar e estruturar sistemas de vigilância e modelos de atenção dirigidos ao evento. ${ }^{4,5}$

A revista Epidemiologia e Serviços de Saúde (RESS), como os demais periódicos brasileiros da área da saúde coletiva, vem acompanhando e participando desse desenvolvimento há quase três décadas. Inicialmente, como Informe Epidemiológico do SUS, objetivava a organização e ampla divulgação de informações epidemiológicas do Ministério da Saúde $;{ }^{6}$ a partir de 2003, este informe deu lugar à RESS, que desde então visa ao aprimoramento dos serviços do Sistema Único de Saúde (SUS), pela difusão do conhecimento epidemiológico aplicável às ações de vigilância, prevenção e controle de doenças e agravos de interesse da saúde pública. ${ }^{7}$

A emergência sanitária global, advinda com a pandemia de COVID-19, tem imposto novos e complexos desafios às sociedades e, neste contexto, a resposta da ciência tem se mostrado rápida e contundente. ${ }^{8}$ No Brasil, até o dia 7 de outubro de 2021, a Plataforma Brasil registrava 13.781 projetos aprovados cujos títulos incluíam 'COVID-19'. Essa produção acelerada de pesquisas, associada à demanda por maiores informações sobre a nova doença, tem se refletido no expressivo volume de publicações científicas sobre o problema nos periódicos científicos brasileiros da área da saúde coletiva, ressaltando-se a publicação de pesquisas originais. Até setembro de 2021, estes periódicos nacionais haviam publicado cerca de 400 artigos em diversas modalidades (Tabela 1).

Nesse cenário, a RESS lançou uma chamada para manuscritos sobre COVID-19 e acelerou seus processos de avaliação (fast-track), o que contribuiu para a disseminação oportuna de evidências. Além de 22 artigos originais, também foram publicados na RESS artigos nas modalidades nota de pesquisa, revisão e opinião, entre outras, os quais, de acordo com pesquisa de dados altimétricos das plataformas SciELO e Plum analítica, registravam mais de 250 mil visualizações e mais de 700 citações até setembro de 2021, demonstrado a elevada visibilidade e impacto dessas publicações. 
Neste último número de 2021 da RESS, os artigos sobre COVID-19 novamente se destacam. São sete artigos originais abordando diferentes temas relacionados à doença, como o seu perfil epidemiológico, repercussões na oferta e organização dos serviços de saúde; mas outras modalidades também aludem à crise sanitária.

A manutenção do elevado volume de submissões e de manuscritos em fase de processamento editorial sobre COVID-19, nestes últimos meses, sugere que ainda estamos longe de uma saturação temática. Com as novas evidências, diferentes atributos são incorporados à discussão e, com seu alcance, a RESS fortalece sua missão de difusora do conhecimento epidemiológico e contribui para o fortalecimento dos serviços de saúde do SUS e para a melhoria das condições de saúde do brasileiro.

Cynthia Braga ${ }^{1}$ - @ orcid.org/0000-0002-7862-6455

Barbara Reis-Santos ${ }^{2}$ - (1) orcid.org/0000-0001-6952-0352

'Instituto Aggeu Magalhães, Fundação Oswaldo Cruz, Recife, PE, Brasil

${ }^{2}$ Ministério da Saúde, Secretaria de Vigilância em Saúde, Brasília, DF, Brasil

\section{Referências}

1. Fine P, Goldacre B, Haines A. Epidemiology: a science for the people. Lancet. 2013;381(9874):1249-52. doi: https://doi. org/10.1016/S0140-6736(13)60766-7.

2. Barreto ML, Papel da epidemiologia no desenvolvimento do sistema único de saúde no Brasil: histórico, fundamentos e perspectivas. Rev Bras Epidemiol. 2002;5(supl 1):4-17. doi: https://doi.org/10.1590/\$1415-790X2002000400003.

3. Albuquerque MFPM, Souza WV, Araújo TVB, Braga MC, Miranda Filho DB, Ximenes RAA, et al. Epidemia de microcefalia e vírus Zika: a construção do conhecimento em epidemiologia. Cad Saude Publica. 2018;34(10):e00069018. doi: https:// doi.org/10.1590/0102-311X00069018.

4. Ministério da Saúde (BR). Orientações integradas de vigilância e atenção à saúde no âmbito da emergência de saúde pública de importância nacional: procedimentos para o monitoramento das alterações no crescimento e desenvolvimento a partir da gestação até a primeira infância, relacionadas à infecção pelo vírus Zika e outras etiologias infeciosas dentro da capacidade operacional do SUS [Internet]. Brasilia, DF: MS; 2017 [acesso 20 out. 2020]. Disponível em: http://bvsms. saude.gov.br/publicacoes/orientacoes_emergencia_gestacao_infancia_zika.pdf

5. França GVA, Pedi VD, Garcia MHO, Carlo GMI, Leal MB, Garcia LP. Síndrome congênita associada à infecção pelo vírus Zika em nascidos vivos no Brasil: descrição da distribuição dos casos notificados e confirmados em 2015-2016. Epidemiol Serv Saude. 2018;27(2):e2017473. doi: https://doi.org/10.5123/S1679-49742018000200014.

6. Silva Junior JB. A trajetória do informe epidemiológico do SUS. Inf Epidemiol SUS. 2002;11(4):201-2. doi: http://doi. org/10.5123/\$0104-16732002000400001.

7. Garcia LP, Duarte E. Epidemiology and health services: the trajectory of the brazilian national health system journal. Cien Saude Colet. 2015;20(7):2081-90. doi: http://doi.org/10.1590/1413-81232015207.06122015.

8. Galvão TF. Resposta da ciência para a pandemia de covid-19: compromisso com a vida. Epidemiol Serv Saúde. 2021;30(2):e2020377. doi: https://doi.org/10.1590/\$1679-49742021000200001. 
Tabela 1 - Número de artigos sobre COVID-19 publicados ${ }^{\mathrm{a}}$ em revistas brasileiras da área de saúde coletiva ${ }^{\mathrm{b}}$, até 30 de setembro de 2021

\begin{tabular}{lcc}
\hline & \multicolumn{2}{c}{ Artigos publicados } \\
Revista & $\mathbf{2 0 2 0 ^ { \mathbf { a } }}$ & $\mathbf{2 0 2 1}^{\mathbf{a}}$ \\
\cline { 2 - 3 } & $\mathbf{n}$ & $\mathbf{n}$ \\
\hline Ciência \& Saúde Coletiva & 118 & 62 \\
Cadernos de Saúde Pública & 66 & 42 \\
Revista de Saúde Pública & 13 & 11 \\
Epidemiologia e Serviços de Saúde & 27 & 11 \\
Saúde em Debate & 48 & 2 \\
\hline Total & $\mathbf{2 7 2}$ & $\mathbf{1 2 8}$ \\
\hline
\end{tabular}

a) Informaçōes extrádas do SciEL0, excluídas as erratas, em 7 de outubro de 2021; b) Cinco primeiras revistas, segundo o ranking do Google Scholar. 